\title{
ARMAZENAMENTO E TRATAMENTOS PRÉ-GERMINATIVOS EM SEMENTES DE JACARANDÁ (Jacaranda cuspidifolia Mart.) $)^{1}$
}

\author{
Silvana de Paula Quintão Scalon ${ }^{2}$, Rosilda Mara Mussury ${ }^{3}$, Homero Scalon Filho ${ }^{4}$, Carla Silvana Fabro \\ Francelino $^{5}$ e Débora Katiuce Augusto Florencio ${ }^{5}$
}

\begin{abstract}
RESUMO - O objetivo deste trabalho foi avaliar o efeito da temperatura, do tempo de armazenamento e de tratamentos pré-germinativos na porcentagem de emergência $(\% \mathrm{E})$ e no índice de velocidade de emergência (IVE) de jacarandá (Jacaranda cuspidifolia Mart.). O experimento foi conduzido em fatorial 5 x 2 x 4 (cinco períodos de armazenamento $(0,30,60,90$ e 150 dias $) \times 2$ temperaturas $\left(12 \pm 2^{\circ} \mathrm{Ce} 25 \pm 2^{\circ} \mathrm{C}\right) \times 4$ tratamentos pré-germinativos (1- Imersão em GA $125 \mathrm{mg} \mathrm{L}^{-1} / 24 \mathrm{~h}$; 2 - Imersão em GA $250 \mathrm{mg} \mathrm{L}^{-1} / 24 \mathrm{~h}$; 3 - Imersão em água quente; 4- Testemunha), em DIC com cinco repetições de 30 sementes. A emergência aumentou de $29 \%$ no tempo zero a $79 \%$ aos 150 dias, sendo que as sementes podem ser armazenadas por 150 dias, alcançando emergência superior a 70\% sem nenhum tratamento pré-germinativo. Embora o IVE não tenha variado entre os tratamentos aos 150 dias nas sementes sob refrigeração (média de 0,82 ) e sob temperatura ambiente, o maior valor foi observado nas sementes tratadas com água quente e GA $250 \mathrm{mg} . \mathrm{L}^{-1}(0,41)$.
\end{abstract}

Palavras-chave: Ácido giberélico, armazenamento e refrigeração.

\section{STORAGE AND PREGERMINATIVE TREATMENTS IN JACARANDÁ (Jacaranda cuspidifolia Mart.) SEEDS}

\begin{abstract}
This work aimed to evaluate the effect of temperature, period of storage and pregerminative treatments on the emergence percentage $(E \%)$ and emergence speed index (SEI) of Jacarandá (Jacaranda cuspidifolia Mart.). The experiment was carried out in factorial $5 \times 2 \times 4$ (5 storage periods $(0,30,60$, 90 and 150 days) $C 2$ temperatures $\left(12 \pm 2^{\circ} \mathrm{C}\right.$ and $\left.25 \pm 2^{\circ} \mathrm{C}\right) \mathrm{C} 4$ pregerminative treatments ( 1 - immersion

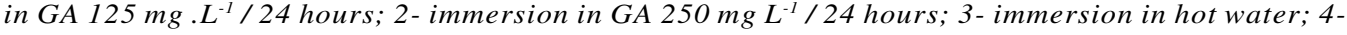
control), in DIC with 5 replications of 30 seeds. The emergence increased from 29\% at the first day to 79 $\%$ at the $150^{\text {th }}$ day. The seeds may be stored for 150 days reaching emergence higher than $70 \%$ without any pregerminative treatment. Although there was no SEI change among the treatments after storage of seeds for 150 days under refrigeration (average 0.82), the highest value was observed with seeds kept at room temperature and treated with hot water and GA $250 \mathrm{mg} . \mathrm{L}^{-1}$ was 0.41 .
\end{abstract}

Keywords: Gibberellic acid, storage and refrigeration.

\footnotetext{
${ }^{1}$ Recebido em 28.04.2004 e aceito para publicação em 10.11.2005.

${ }^{2}$ Universidade Federal de Mato Grosso do Sul.

${ }^{3}$ Centro Universitário da Grande Dourados (UNIGRAN).

${ }^{4}$ Universidade Estadual de Mato Grosso do Sul.

${ }^{5}$ Acadêmicas de Ciências Biológicas/UNIGRAN; Rodovia Dourados-Ithaum, km 12, 79.804-970 Dourados, MS, Brasil. E.mail: <sscalon@ceud.ufms.br>.
} 


\section{INTRODUÇÃO}

As informações disponíveis em tecnologia de sementes de espécies nativas, visando à preservação e qualidade das sementes por determinado período de tempo, são escassas. Determinadas espécies não devem ser semeadas logo após a colheita, sendo suas sementes armazenadas para evitar deterioração. Condições de baixa temperatura e umidade são recomendadas para armazenar a maioria das sementes (VERTUCCIe ROOS, 1993), embora outras espécies apresentem exigências diferentes. As condições de armazenamento irão interferir no período máximo desse armazenamento e na germinação final das sementes, podendo até levar a semente a algum tipo de dormência secundária.

A distribuição da capacidade de germinação no tempo ocorre nos vegetais devido a diferentes intensidades de dormência de suas sementes. Dessa forma, numa mesma planta pode haver sementes prontas para germinar e outras que germinarão após meses ou anos (CARVALHO e NAKAGAWA, 2000). Os principais fatores que provocam a dormência são temperatura, luz, resistência do tegumento, presença de inibidores e imaturidade fisiológica do embrião.

A rapidez de deterioração das sementes de algumas espécies nativas é muito elevada, e o período em que a viabilidade pode ser mantida varia de algumas semanas a poucos meses, de tal maneira que as pesquisas sobre armazenamento de sementes de espécies florestais nativas assumem caráter de extrema importância (CARNEIRO e AGUIAR, 1993).

O jacarandá (Jacaranda cuspidifolia Mart.), conhecido como caroba, jacarandá e bolacheira, pertencente à família Bignoniaceae, é uma árvore de médio porte com altura de 3-10 m, apícola, utilizada na arborização e ornamentação de ruas, principalmente devido a beleza de suas flores arroxeadas. A planta é decídua, heliófita, pioneira e xerófita, características de encostas rochosas da floresta latifoliada e transição para o cerrado. Produz anualmente grande quantidade de sementes viáveis, amplamente dispersas pelo vento, e floresce durante os meses de setembro/dezembro com as plantas totalmente despidas de sua folhagem velha (POTTe POTT, 1994; LORENZI, 2000). Em revisão de Pott e Pott (1994), observou-se que a planta apresenta propriedades inseticidas, sendo a raiz utilizada para tratamento de sarna; é depurativa e excelente contra desinteria; e a madeira, casca e folha são utilizadas para combater febre.

R. Árvore, Viçosa-MG, v.30, n.2, p.179-185, 2006
Relatos sobre armazenamento e germinação de J. cuspidifolia são escassos na literatura consultada, embora o gênero Jacaranda venha sendo estudado.

Lorenzi (2000) relatou que as sementes de $J$. cuspidifolia apresentam germinação superior a $80 \%$ e germinam em 12-25 dias, apresentando baixa viabilidade sob armazenamento que não ultrapassa quatro meses. A germinação das sementes é epígea e ocorre no sexto dia após a semeadura, mantendo os cotilédones por 30 dias (CONTINI et al., 2003).

As sementes de Jacaranda acutifolia toleram secagem e armazenamento em temperatura de $-20{ }^{\circ} \mathrm{C}$ $\mathrm{a}+5^{\circ} \mathrm{C}$, atingindo porcentagem de germinação superior a $60 \%$, sendo consideradas ortodoxas e podendo ser conservadas por até 24 meses. Em temperatura ambiente, as sementes podem manter a viabilidade somente durante seis meses, com germinação em torno de $80 \%$, após os quais ocorre queda significativa do poder germinativo das sementes, chegando a zero aos 18 meses (MELLO e EIRA, 1995). A viabilidade das sementes de $J$. micrantha foi mantida quando armazenadas em sacos plásticos em câmara fria $\left( \pm 5^{\circ} \mathrm{C}\right)$ por 12 meses (RAMOS, 1980).

O uso de reguladores de crescimento que estimulem a germinação de sementes de algumas espécies vegetais nativas é importante, e nesse contexto o emprego da giberelina tem sido fundamental, pois está relacionado com a síntese de enzimas hidrolíticas que degradam reservas como amido e proteínas, que são usadas no desenvolvimento do embrião e também no alongamento da radícula. O baixo índice de germinação e heterogeneidade das plântulas emergidas pode ser resultado do balanço entre promotores e inibidores de crescimento. Assim, pode ser empregado o ácido giberélico na promoção da germinação, pois este, dentre outros fatores, promove aumento do alongamento celular (TAIZ e ZEIGER, 1991; SALISBURY e ROSS, 1992). Pesquisas comprovam que o uso do ácido giberélico em sementes de diversas espécies arbóreas estimula a germinação, assim como vários outros grupos de giberelinas e citocininas têm apresentado resultados satisfatórios (CASTRO et al., 1999; JELLER e PEREZ, 1999; FERREIRA et al., 2001).

Bruno et al. (2001), em sua revisão, observaram que o tratamento das sementes com água quente ou fervente é muito utilizado em várias espécies florestais, tendo sido comprovada a sua eficiência na superação 
da dormência de várias espécies, como Mimosa scabrella Benth., Acacia sp., Acacia mearnsii Willd e Parkinsonia aculeata (DC) O. Kuntze. Entretanto, apesar de ser um método vantajoso, de baixo custo e eficiente para superar a dormência de sementes, pode ter pouca eficiência ou até inibir a germinação de algumas espécies de leguminosas, como Senna macranthera (Colladon) Irwin e Barneby, Copaifera langsdorfii Desf., Enterolobium contorsiliquum (Vell.) Morong. e Mimosa caesalpiniaefolia Benth..

Este trabalho teve como objetivo avaliar os efeitos do tempo e da temperatura de armazenamento e de tratamentos pré-germinativos sobre a emergência de plântulas de jacarandá.

\section{MATERIAL E MÉTODOS}

O experimento foi realizado em Dourados, MS, no ano de 2001 . A cidade está situada a $22^{\circ} 13$ ' $16^{\prime \prime}$ de latitude sul e $54^{\circ} 48^{\prime} 2^{\prime}$ ' de longitude oeste e tem altitude média de $452 \mathrm{~m}$. O clima é classificado como Cwa, e a precipitação média anual é de $1.500 \mathrm{~mm}$, com temperatura média anual de $22^{\circ} \mathrm{C}$.

Os frutos de jacarandá foram colhidos de árvores, na cidade de Dourados, sendo as sementes separadas em lotes, no Laboratório de Botânica do Centro Universitário da Grande Dourados (UNIGRAN). As sementes foram armazenadas em ambiente refrigerado $\left(12 \pm 2^{\circ} \mathrm{C}\right)$ e em temperatura ambiente $\left(25 \pm 2^{\circ} \mathrm{C}\right)$ por 0, 30, 60, 90 e 150 dias. Após cada período de armazenamento, as sementes foram retiradas e tratadas com hipoclorito de sódio $1 \%$ por 10 min, para desinfecção (BRASIL, 1992), e imersas nos seguintes tratamentos pré-germinativos: 1) ácido giberélico $125 \mathrm{mg} \mathrm{L}^{-1}$, por $24 \mathrm{~h} ; 2$ ) ácido giberélico $250 \mathrm{mg} \mathrm{L}^{-1}$, por $24 \mathrm{~h}$; 3 ) água quente (imersão na água fervida e após esfriar, permanência por 24 h); e 4) sem pré-embebição (testemunha) e posteriormente semeadas. A semeadura logo após a coleta das sementes e antes do armazenamento serviu como referência, sendo considerado tempo zero.

Na casa de vegetação da UNIGRAN, a semeadura foi realizada a $2 \mathrm{~cm}$ de profundidade, em sacos plásticos com dimensões de $15 \mathrm{~cm}$ de altura x $5 \mathrm{~cm}$ de largura, contendo como substrato areia e solo (1:2) adubado com NPK (4-14-8 em $2 \mathrm{~kg} / \mathrm{m}^{3}$ de solo). A capacidade de emergência das sementes foi determinada pelo índice de velocidade de emergência (IVE), e a porcentagem de emergência (\%E) o foi segundo Popinigis (1985).
O experimento foi conduzido em delineamento inteiramente casualizado em fatorial 5 (períodos de armazenamento) X 2 (temperaturas) X 4 (tratamentos pré-germinativos), com cinco repetições de 30 sementes (2 sementes/recipiente).

Os resultados foram submetidos à análise de variância e as médias, comparadas pelo teste de Tukey a $5 \%$ de probabilidade.

\section{RESULTADOS E DISCUSSÃO}

A partir da análise dos resultados, pôde-se verificar que não ocorreram diferenças significativas na interação entre os fatores temperatura, tempo e tratamentos prégerminativos para os parâmetros avaliados. Portanto, os resultados foram avaliados separadamente.

As sementes armazenadas sob refrigeração apresentaram porcentagens de emergência maiores do que as armazenadas na temperatura ambiente, em todos os períodos de armazenamento (Figura 1), apresentando valores médios de 54,7 e $41,4 \%$, respectivamente. A refrigeração pode ter reduzido as reações metabólicas do embrião, conservando melhor o vigor das sementes.

O armazenamento e a refrigeração são importantes no incremento da emergência das sementes de jacarandá, as quais não devem ser semeadas logo depois de extraídas do fruto, pois se observou que a porcentagem de emergência aumentou com o período de armazenamento e com a refrigeração (Figura 1a e Tabela 1).

Esses resultados apontam que as sementes recémcolhidas do fruto ainda não estavam em plena maturidade fisiológica, pois somente com o passar dos dias é que foi aumentando a emergência, embora aos 30 dias de armazenamento essa porcentagem tenha reduzido, o que pode ser atribuído a algum mecanismo de adaptação à condição de armazenamento.

Os tratamentos pré-germinativos não superaram a porcentagem de emergência das sementes-testemunha, entretanto o tratamento com GA $125 \mathrm{mg} . \mathrm{L}^{-1}$ aumentou o índice de velocidade de emergência (Tabela 1). Em média, os tratamentos com giberelina não proporcionaram aumento na emergência das sementes armazenadas sob refrigeração somente naquelas armazenadas sob temperatura ambiente aos 60 e 90 dias (Figura 2). No início do armazenamento, provavelmente as sementes possuíam quantidade endógena de giberelina suficiente, e a suplementação pode ter causado efeito inibidor.

R. Árvore, Viçosa-MG, v.30, n.2, p.179-185, 2006 

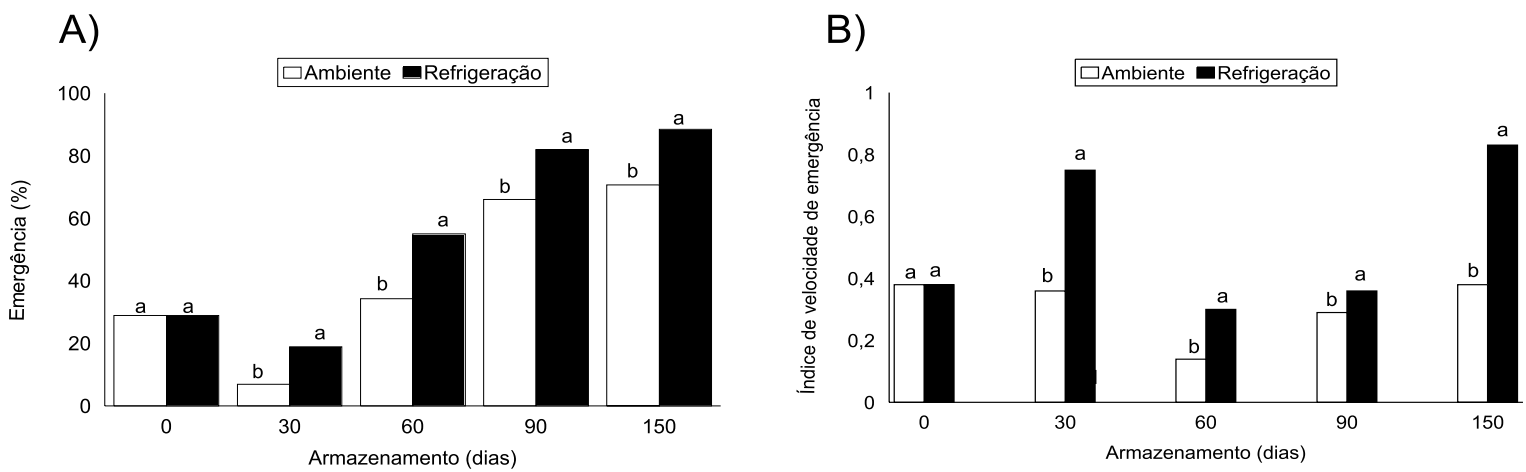

Figura 1 - Porcentagem de emergência (a) e índice de velocidade de emergência (b) de sementes de jacarandá (Jacaranda cuspidifolia) armazenadas por diferentes períodos sob temperatura ambiente e sob refrigeração. UNIGRAN, Dourados, MS, 2001.

Figure 1 - Emergence percentage (a) and speed of emergence index (b) of jacaranda (Jacaranda cuspidifolia) seeds stored for different periods at room temperature and under refrigeration. UNIGRAN, Dourados, MS. 2001.

Tabela 1 - Emergência (\%) e índice de velocidade de emergência de sementes de jacarandá (Jacaranda cuspidifolia) Table 1-Emergency (\%) and emergency speed index of jacaranda (Jacaranda cuspidifolia) seeds

\begin{tabular}{rrrl}
\hline & & Emergência $(\%)$ & IVE \\
\cline { 3 - 4 } Dias & 0 & $29,0 \mathrm{~d}$ & $0,38 \mathrm{c}$ \\
& 30 & $13,0 \mathrm{e}$ & $0,54 \mathrm{~b}$ \\
& 60 & $44,6 \mathrm{c}$ & $0,22 \mathrm{e}$ \\
& 90 & $74,0 \mathrm{~b}$ & $0,32 \mathrm{~d}$ \\
\hline \multirow{4}{*}{ Tratamentos } & 150 & $79,2 \mathrm{a}$ & $0,59 \mathrm{a}$ \\
& Testemunha & $58,8 \mathrm{a}$ & $0,47 \mathrm{~b}$ \\
& Água quente & $41,8 \mathrm{c}$ & $0,18 \mathrm{c}$ \\
& GA 125 & $42,1 \mathrm{c}$ & $0,51 \mathrm{a}$ \\
\hline
\end{tabular}

Médias seguidas da mesma letra minúscula na coluna não diferem estatisticamente entre si, pelo teste de Tukey a $5 \%$.

A)

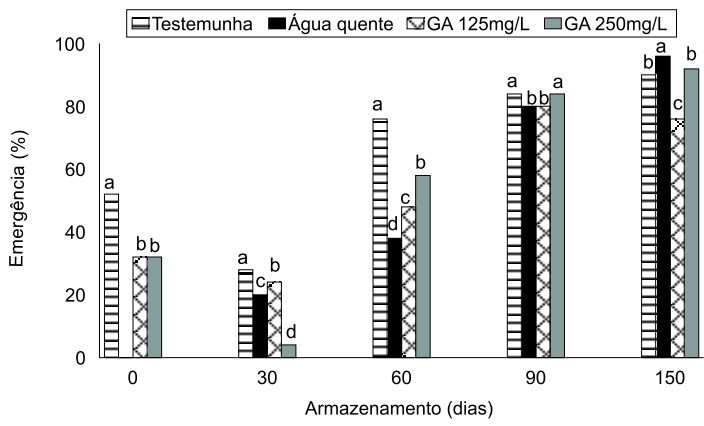

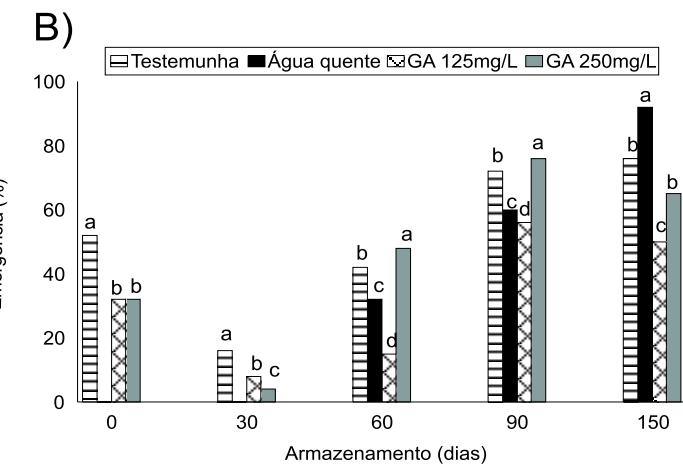

Figura 2 - Porcentagem de emergência de sementes de jacarandá (Jacaranda cuspidifolia) armazenadas sob refrigeração(a) e temperatura ambiente (b) e diferentes tratamentos pré-germinativos. UNIGRAN, Dourados, MS, 2001.

Figure 2 - Emergence percentage of jacaranda (Jacaranda cuspidifolia) seeds stored under refrigeration (a) and room temperature (b) and subjected to pregerminative treatments. UNIGRAN, Dourados, MS, 2001.

R. Árvore, Viçosa-MG, v.30, n.2, p.179-185, 2006 
Altos níveis de giberelina são encontrados em sementes imaturas de algumas espécies (ARTECA, 1996). $\mathrm{O} \mathrm{GA}_{3}$ produzido no embrião é transferido para a camada de aleurona das células, onde a a-amilase é produzida via síntese "de novo", a qual promove a conversão do amido em açúcar, que é usado, então, para o crescimento da plântula.

Aos 0, 30 e 60 dias de armazenamento sob refrigeração, as sementes-testemunha (sem préembebição) apresentaram porcentagem de emergência significativamente maior em relação aos outros tratamentos (Figura 2), comprovando que, nos períodos iniciais de armazenamento das sementes de jacarandá, não se faz necessária à aplicação de giberelina.

Aos 90 dias, a utilização de GA 250 aumentou significativamente a porcentagem de emergência no ambiente, entretanto, após 150 dias sob temperatura ambiente ou sob refrigeração, o tratamento com água quente foi significativamente superior, alcançando 92 a 96\% de emergência, não sendo necessária a aplicação de giberelina.

As sementes de jacarandá puderam ser armazenadas por 150 dias sob temperatura ambiente ou refrigeração, sem necessitar de nenhum tratamento para alcançar uma média de 76 a $90 \%$ de emergência, respectivamente. Esses resultados contradizem aqueles relatados por Lorenzi (2000), que considerou que as sementes de J. cuspidifolia apresentam curta vida de armazenamento.

O tratamento com água quente em ambas as temperaturas de armazenamento foi prejudicial ao processo de germinação, principalmente ao ser utilizado

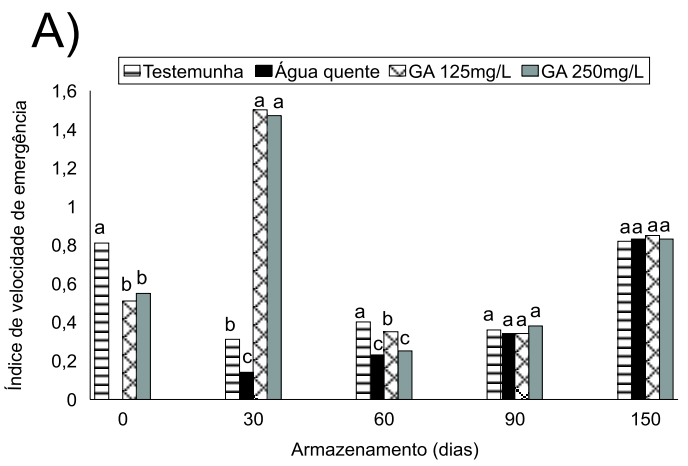

quando a semeadura ocorre logo após a retirada das sementes do fruto ou após 30 dias de armazenamento sob temperatura ambiente; provavelmente, pode ter causado algum tipo de injúria ao embrião. Aágua quente apresentou resultados significativos tanto para porcentagem de emergência quanto para IVE somente após 150 dias de armazenamento refrigerado ou sob temperatura ambiente.

Comportamento semelhante ao da porcentagem de emergência foi observado para o IVE que, embora tenha oscilado durante o armazenamento, aumentou do tempo zero para 150 dias, sendo que a refrigeração manteve o IVE maior que sob temperatura ambiente. Em média, o IVE foi significativamente maior nas sementes armazenadas sob refrigeração $(0,51)$ aos 150 dias de armazenamento $(0,59)$ e tratadas com GA $125 \mathrm{mg} . \mathrm{L}^{-1}$ $(0,51)$ (Figura 1 b e Tabela 1$)$.

No tempo zero, as sementes-testemunha apresentaram maior IVE $(0,81)$, indicando que os tratamentos com GA podem ter inibido os processos de germinação. No tempo 30 , as sementes tratadas com giberelina e armazenadas sob refrigeração apresentaram praticamente o dobro de IVEdas sementes tratadas com GA $125 \mathrm{mg} . \mathrm{L}^{-1} \mathrm{e}$ armazenadas sob temperatura ambiente. Nos demais tempos de armazenamento, os tratamentos com giberelina não variaram significativamente dos demais tratamentos.

Aos 150 dias, embora o IVE tenha sido maior e não tenha variado entre os tratamentos para as sementes sob refrigeração (média de 0,82 ), sob temperatura ambiente, alcançou o maior valor naquelas sementes tratadas com água quente e GA 250 (média de 0,41) (Figura 3).

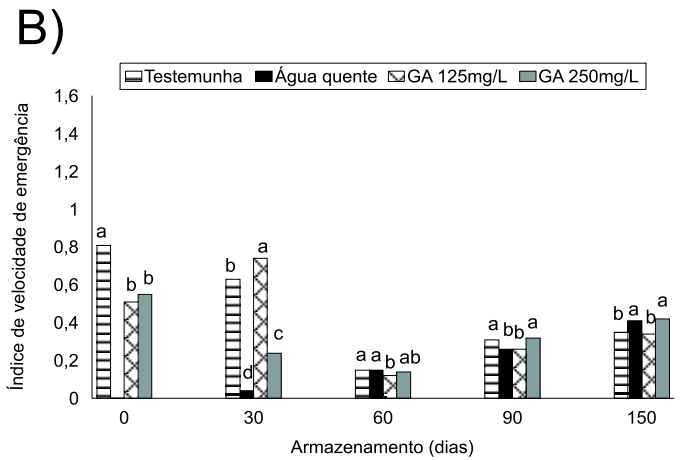

Figura 3 - Índice de velocidade de emergência de sementes de jacarandá (Jacaranda cuspidifolia) armazenadas sob refrigeração (a) e temperatura ambiente (b) e diferentes tratamentos pré-germinativos. UNIGRAN, Dourados, MS, 2001.

Figure 3 - Emergence speed index of jacaranda (Jacaranda cuspidifolia) seeds stored under refrigeration (a) and room temperature (b) and subjected to pregerminative treatments. UNIGRAN, Dourados, MS, 2001.

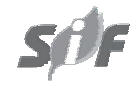

R. Árvore, Viçosa-MG, v.30, n.2, p.179-185, 2006 
Ferreira et al. (2001) consideraram que o emprego dos fitorreguladores em Annona cherimola Mill e Annona squamosa L. não eleva a porcentagem de emissão da radícula. Entretanto, de modo geral, proporciona elevada porcentagem de plântulas normais e elevado IVG, destacando-se as concentrações de $750 \mathrm{mg} \mathrm{L}^{-1} \mathrm{de} \mathrm{GA}_{3}$ e de $50 \mathrm{mg} \mathrm{L}^{-1} \mathrm{de} \mathrm{GA}_{4+7}+\mathrm{N}$-(fenilmetil)-1H6-aminopurina.

Baseado nos resultados de germinação do jacarandá e considerando o elevado custo da giberelina, sugerese que esse tratamento não deva ser recomendado para o processo de produção de mudas dessa espécie.

\section{CONCLUSÃO}

A porcentagem de emergência aumentou com o período de armazenamento, sendo maior sob refrigeração. As sementes puderam ser armazenadas por 150 dias, tanto em temperatura ambiente quanto sob refrigeração, apresentando elevada emergência mesmo sem nenhum tratamento.

\section{AGRADECIMENTOS}

Ao Sr. Paulo Zafra, pela colaboração na condução dos trabalhos de campo.

\section{REFERÊNCIAS BIBLIOGRÁFICAS}

ARTECA, R.D. Plant growth substances: principles and applications. New York: Chapman \& Hall, 1996. 332p.

BRASIL. Ministério da Agricultura e Reforma Agrária. Regras para análise de sementes. Brasília: Coordenação de Laboratório Vegetal - CLAV. Departamento Nacional de Defesa Vegetal, 1992.365p.

BRUNO, R.L.A. et al. Tratamentos pré-germinativos para superar a dormência de sementes de Mimosa caesalpiniaefolia Benth. Revista Brasileira de Sementes, v.23, n.2, p.136-143, 2001.

CARNEIRO, J.G.A.; AGUIAR, I.B. rmazenamento de sementes. In: AGUIAR, I.B.; FIGLIOLA, M.B. (Ed). Sementes florestais tropicais. Brasília:ABRATES, 1993. p.333-350.

CARVALHO, N.M.; NAKAGAWA, J. Sementes: ciência, tecnologia e produção. 4.ed. Jaboticabal: FUNEP, 2000. 588 p.

CASTRO, E.M. et al. Influência do ácido giberélico e do nitrato de potássio na germinação de Guarea guidonea (L.) Sleumer. Revista Árvore, v.23, n.2, p. 255-258. 1999.

R. Árvore, Viçosa-MG, v.30, n.2, p.179-185, 2006
CONTINI, A.Z. et al. Caracterização morfológica da germinação e desenvolvimento inicial de Enterolobium timbouva Mart. (Leguminosae Mimosoidea) e Jacaranda cuspidifolia Mart. (Bignoniaceae). In: CONGRESSO NACIONAL DE BOTÂNICA, 54, Belém, 2003, Resumos. CDROM. Não paginado.

FERREIRA, G.; SEIDEL, G.O.; VERONA, M.M. Efeito de fitorreguladores na germinação de sementes de atemóia (Annona cherimola Mill. X Annona squamosa L.) In: CONGRESSO NACIONAL DE FISIOLOGIA VEGETAL, 8., 2001, Ilheus. Resumos. Ilhéus: 2001. CDROM.

JÉLLER, H.; PEREZ, S.C.J.G.A.A. Dormência e temperatura em sementes de Cassia excelsa 1999), Revista Brasileira de Sementes, v.21, n.1, p. 41-45, 1999.

LORENZI, H.. Árvores Brasileiras. 3. ed. Nova Odessa: Plantarum, 2000. 352p.

MELLO, C.M.C.; EIRA, M.T.S. Conservação de sementes de jacarandá mimoso (Jacaranda acutifolia Humb \& Bompl.)- Bignoniaceae.

Revista Brasileira de Sementes, v.17, n.2, p.193-196, 1995.

POPINIGS, F.. Fisiologia da semente. Brasília: Agiplan, 1985. 289p.

POTT, A.; POTT, V.J. Plantas do Pantanal. Corumbá: Empresa Brasileira de Pesquisa Agropecuária do Pantanal, 1994. 320 p.

RAMOS, A. Influência de cinco tipos de embalagens na germinação e no vigor de sementes de angico - Paraptadenia rigida (Benth.) Brenan, caixeta Tabebuia cassinoides (Lam.) DC e caroba - Jacaranda micrantha (Cham.) armazenadas em câmara fria e à temperatura ambiente. 1980. 134f. Dissertação (Mestrado em Engenharia Florestal) Universidade Federal do Paraná, Curitiba, 1980.

SAlisBURY, F. B.; ROSS, C. W. Plant physiology. 4. ed. Califórnia,:Wadsworth, 1992. 682p. 
TAIZ, L.; ZEIGER, E. Plant physiology.

California: The Benjamin/ Cummings Publishing. 1991.559p.
VERTUCCI, C.W.; ROSS, E.E. Seed storage, temperature and relative humidity:response. Seeds Science Research, v.3, n.3, p.215-216, 1993. 